\title{
ORGANIZAÇÃO E RELAÇÕES DE TRABALHO EM HOTELARIA NA CIDADE DE NATAL'
}

\author{
Maria das Graças de Menezes Venáncio Paiva²
}

\begin{abstract}
RESUMO: Discuie a questão da tecnologia retida pelos hotéis de Natal (RN), pertencentes a empresários e/ou grupos empresariais da regiăo Nordeste, pressupondo que esta abrange a organizaçăo e as relaçēes de trabaiko. En termos metodológicos é feita uma comparação com um hotel de propriedade de empresário local, mas arrendado a uma cadeia intemacional integrante de umia holding detentora de tecnologia emhotelaria, comos demaishotéispesquisados. Contrapõem-se duas lógicas. A primeira, homogêna quanto à gestão de recursos humanos e controlada à distância; a segunda, fragilizada em face do atual estágio de expansão do turismo nordestino. No nivel teórico são feitas considerações sobre tecnologia, organização e relações de trabalho, e sistema de mediações usados pelas orgasizações hipermodernas.
\end{abstract}

PALAVRAS-CHAVE: Hotelaria; hotéis; tecnologia, organizaçãoe relações de trabalho; Natal; Rio Grande do Norte; Brasil; estudo comparativo.

ABSTRACT: The text discusses the technology held by hotels in Natal (RN), city belonging to individual entrepreneurs or economic groupe from the northeastern Brazilian region, pressuming that technology involves organization and labour relationship. In methodologicalterms a comparison is made amongst a hotel owned by a local individual entrepreneur - but leased to a holding attached international chain-and the other hotels. Two logicsare compared. Thefirstone, homogeneous intermsof human resources management and controlled from abroad. The second one, weakened due to the present stage of Northeastern tourism development. Some theoretical considerations are made, also, about technoiogy, management, labour relationship and the mediation system applied by posmodernorganizations.

1 Trabalho originalmente apresentado no "I Simpósio Latino-Americano de Docentes e Pesquisadores Cientificos de Turismo", realizado em novembro de 1993, em Salvador, Bahia, Brasil.

2 Mestre em Administração Pública pela Escola de Administração Pública da Fundação Getúlio Vargas. Especialista em Desenvolvimento Turistico pela SUDENE. Professora de Graduação e Pós-Graduação em Administração da Universidade Federal do Rio Grande do Norte.

End. para corresp.: Rua Dom Joaquim de Almeida, 2076 - Bloco A/603 - Morro Branco - 59050140 - Natal - RN - Brasil. 
KEY WORDS: Hospitality resources; hotels; technology, organization and labour relationship; Natal; Rio Grande do Norte; Brazili; comparative study.

\section{INTRODUÇÃO}

A razão que motivou a realização da pesquisa tratada neste artigo, intitulada Tecnologia Hoteleira: Organização do Processo de Trabalho e Relações de Trabalho nos Hotéis do Nordeste, foi a necessidade de reconstituir a tecnologia existente e conhecer o posicionamento das empresas hoteleiras locais no mercado. Parte-se da premissa que o turismo da região Nordeste ingressou na década de 90 numa etapa de internacionalização caracterizada pela chegada de investimentos dos oligopólios, que controlam os fluxos internacionais, o que pode representar um risco de inserção fragilizada para as empresas pertencentes a empresários e/ou grupos empresariais do Estado do Rio Grande do Norte ou da região Nordeste.

Para RATTNER (1980:11-4), a análise das inovações tecnológicas em face do desenvolvimento, ora privilegia o enfoque sistêmico funcionalista da administração tecnológica das empresas visando objetivos pragmáticos de melhoria das técnicas de gestão e aperfeiçoamento da tecnologia, ora procura entender a inserção do setor ante as condições histórico-estruturais em países de capitalismo tardio. Admite-se que esses dois enfoques não são excludentes quanto ao estudo realizado. No entanto, não se prendendo a uma ótica exclusivamente sistêmica, dá-se maior ênfase aos aspectos técnicos organizacionais, embora seja feita uma contextualização da evolução da hotelaria no Brasil no decorrer do texto.

Neste sentido, THIOLLENT (1983:60-1), ao discorrer sobre a metodologia mais apropriada para osestudos no campo técnico-organizacional, situa que a organização do processo de trabalho e da tecnologia não corresponde apenas ao componente material de transformação física, mas também ao componente normativo que visa a redução dos problemas de produção e de outros processos. VARGAS (1983) entende que a tecnologia não diz respeito somente a máquinas, equipamentos, técnicas ou mercadorias, mas corresponde ao conhecimento formalizado proveniente tanto das técnicas, sendo orientado para um fim prático, como decritérios provenientes das relações sociais e econômicas.

As relações de trabalho por sua vez refletem as "relações sociais, econômicas e políticas da sociedade abrangente" e a sua compreensão deve considerar o espaço social e político em que se realiza, ou seja, a organização do processo de trabalho, a elaboração das políticas administrativoorganizacionais e a prática cotidiana dos agentes sociais.
Tentar compreender os aspectos técnico-organizacionais da hotelaria implica no entendimento da complexidade das relações de trabalho e viceversa, quando se propõe uma abordagem mais crítica, embora tal objetivo não seja alcançado se não forem respeitados os aspectos maisfuncionais do setor hoteleiro.

\section{METODOLOGIA}

Para efeito da pesquisa escolheu-se de maneira intencional um hotel pertencente a um empresário local, mas explorado por uma cadeia internacional, como parâmetro de comparação com os demais hotéis pesquisados.

A escolha do hotel-parâmetro ocorreu devido à facilidade de acesso $\mathrm{e}$ ligação a um sistema já consolidado, que ressalta, na sua filosofia, o treinamento e a valorização dos recursos humanos como fundamentais a sua atuação.

Os demais hotéis pesquisados foram selecionados de acordo com os seguintes critérios:

a) ser de propriedade de grupo local ou regional;

b) conciliar lazer e negócios;

c) atender a uma demanda que exige serviços de melhor qualidade;

d) demonstrar acessibilidade aos pesquisadores.

\section{CENÁRIO dA HOTELARIA NO BRASIL}

\subsection{Fase Pioneira}

No Brasil, a hotelaria teve sua origem com as hospedarias pertencentes a portugueses, na maioria das vezes integradas a empórios de secos e molhados, e localizadas na própria moradia do proprietário. Com a abertura dos portos às nações amigas por d. João VI em 1808, esse monopólio foi desestabilizado por lei, passando a beneficiar também brasileiros.

Em 1816, foi instalado o primeiro hotel de classe internacional no Rio de Janeiro, de propriedade de um francês - Louis Pharoux. A partir de então expandiram-se pequenos hotéis que já incorporavam nas suas instalações características dos hotéis estrangeiros quanto a técnicase operações. Data de 1923 a inauguração do Copacabana Palace e, posteriormente, do Hotel Glória. Ambos implantados no Rio de Janeiro, reproduziam o padrão europeu em serviços e instalações. 
Na década de 40 foram construídos os hotéis cassinos em estâncias como Poços de Caldas (Minas Gerais), Águas de Lindóia, Aguas de São Pedro e Santos (São Paulo), e Petrópolis (Rio de Janeiro). Essas cidades tornaram. se pólos turísticos com o movimento dos cassinos até 1946, quando o jogo foi proibido pelo governo federal (CHIAVASSA \& CHIAVASSA, 1992:61-2).

\subsection{Fase da Política de Incentivos do Estado}

A partir da década de 60 , processou-se uma verdadeira revolução na hotelaria brasileira, sobretudo em decorrência da política de incentivos fiscais e financeiros adotada pelo Estado que, de certa forma, se ajustava ao novo padrão de acumulação do país. Segundo documento da então Empresa Brasileira de Turismo, o

Brasil era carente em hotelaria näo somente em guantidade, mas também em qualidade (EMBRATUR, 1987).

Evidentemente, a inquietação com serviços e instalações que pudessem resultar em qualidade, passava ao largo da preocupação com a reprodução da força de trabalho a ser ocupada no setor hoteleiro.

A partir do decreto-lei n. 55, de 11/11/1966, o governo brasileiro criou EMBRATUR, ligada ao Ministério da Indústria e do Comércio, e 0 Conselho Nacional de Turismo (CNTur). A construção, ampliação ou reforma de hotéis foram equiparados à instalação e ampliação de indústrias básicas, e deveriam gozar de isenção de todos os tributos, exceto da previdência por dez anos. $\mathrm{O}$ decreto também dispunha sobre a possibilidado dos empresários usarem até $50 \%$ do Imposto de Renda e adicionais não restituiveis para investimentos na construção, ampliação e/ou reforma de hotéis.

Nos anos subseqüentes um elenco de leis e decretos viria aperfeiçoar os mecanismos de incentivos, regulamentação e estruturação das atividades turísticas, dentre as quais a hotclaria. Das facilidades oferecidas, as mais incisivas foram o Fundo Geral de Turismo (FUNGETUR, 1971), o Fundo de Investimentos Setorial de Turismo (FISET, 1974), além da possibilidade de obtenção dos recursos do Fundo de Investimento do Nordeste (FINOR) e do Fundo de Investimento da Amazônia (FINAM), nas regiões Nordeste e Norte.

Para CASTELLI (1982) e GOMES (1978), a política de promoção de investimento do governo destinada à hotelaria terminou por privilegiar grupos de estrangeiros, o que demandou evasão de divisas e beneficiamento dos países desenvolvidos que sediam as grandes corporações.
Conforme CHIAVASSA \& CHIAVASSA (1992), em 1970 a cadeia Hilton montou o São Paulo Hilton c a partir desse ano chegaram as redes Holliday Inn, Caesar Park, Novotel, Sheraton, Meridien, Club Med, entre outras. Para esses autores, a implantação de um hotel de cadeia internacional tende a influenciar o mercado no que se refere à atualização aos novos padrões dos serviços oferecidos. Todavia, para os hotéis nacionais não basta assimilar técnicas modernas, adaptando-as às carências dosmercados, masé prioritário a adoção de inovações particulares

\subsection{Situação Atual}

Uma análise realizada por IGNARRA (1989:58-62) chama a atenção para os seguintes aspectos relativos à hotelaria brasileira, além da precariedade das estatísticas que impedem dimensionar com precisão o setor:

a) a fragilidade dos mecanismos de controle sobre a remessa de lucros para o Exterior;

b) a concentração do faturamento nos maiores gnupos hoteleiros (de um total de 273 empresas pesquisadas, cerca de 40 detinham 50\% do faturamento total);

c) o crescimento do setor apesar da crise e até uma certa independência quanto ao apoio do Estado, uma vez que prevalecia os recursos privados no montante dos investimentos realizados.

Já na década de 90

a induistria hoteleira do Brasil atravessa uma crise, apesar de persistirem os investimentos, inclusive de grupos estrangeiros (FOLHA ..., 1991:9)

Houve uma queda na entrada de turistas de outros países e uma redução das viagens internas, devido ao declínio do poder aquisitivo da população. Quanto ao Nordeste, dados mais recentes demonstram que essa crise fo amenizada nos períodos de alta estação, em virtude das mudanças dos destinos turísticos tradicionais do país para a região

A rede hotcleira nordestina representa cerca de $17 \%$ da oferta hoteleira brasileira, sendo superada pelas regiões Sudeste (47\%) e Sul (25\%), conforme dados da EMBRATUR (1991).

Em 1991, a rede hoteleira da grande Natal totalizava 29 hotéis, 2.020 unidades habitacionais e 4.482 leitos, sem considerar as pousadas. Na rede 
hoteleira apenas 2 hotéis são explorados por cadeias nacionais, não sediadas na região Nordeste, e l é arrendado a um grupo internacional.

\section{CONSIDERAÇÕES TEÓRICAS}

Conforme FLEURY \& VARGAS (1983), há pelo menos três métodos para organizar o trabalho: a administração científica, o enriquecimento de cargos e os grupos semi-autônomos.

Os principios tayloristas foram de certa forma disseminados devido à internacionalização das normas de produção e consumo, embora amoldados a cada formação histórica e cada setor de atividade. Sua tônica consiste na estruturação de trabalho, através da racionalização das tarefase formalização dos cargos do sistema produtivo.

Já o enriquecimento de cargos tem por objetivo a maior produtividade com base na satisfação do empregado com o trabalho, prevendo a rotação de cargos e ampliação horizontal e vertical.

Os grupos semi-autônomos, originários da concepção sociotécnica, pressupõem a autonomia de uma equipe, que planeja e organiza o trabalho de acordo com as tarefas e as características da personalidade dos membros da equipe (FLEURY \& VARGAS, 1983:17-37).

MOTTA (1991:160-5), ao analisar a participação direta, ou seja, a participação do trabalhador nas tarefas, afirma que a democratização nas organizações modernas no nível das tarefas visa a maior autonomia do trabalhador, a cooperação entre trabalhadores, a difusão de informações e a motivação no desempenho, o que consequientemente acarreta um comprometimento com a empresa.

Nos últimos anos tem-se o planejamento participativo, os círculos de controle de qualidade e os processos grupais para a decisão e ação, bem como outras formas de organizar o trabalho, de certa maneira influenciados pela experiência japonesa.

Observa-se, na verdade, que os métodos inovadores de operacionalizar o trabalho refletem mudanças no espaço socioeconômico e político, com amplas repercussões nas relações de trabalho e nas orientações da gestão organizacional. Essas estratégias são inclusive vistas criticamente como respostas ao atual estágio de desenvolvimento capitalista, bem representado pela organização hipermoderna, que pode ser analisada como

um sistema econômico-politica-ideológico-psicológico de mediação eocultação de contradiçōes sociais e psicológicas (PAGÉS et al., 1990:16).

\section{ANÁLISE DOS RESULTADOS}

\subsection{Tecnologia em Hotelaria}

A hotelaria se baseia na prestação de serviços que obedecem a uma divisão de trabalho não-parcelada, o que requer dos trabalhadores do setor uma visão total do funcionamento da empresa. Por se fundamentar na prestação de serviços, a tecnologia em hotelaria se fundamenta muito mais no processo organizatório do trabalho, centrado em recursos humanos qualificados, do que em máquinas e equipamentos. SILVA (1990:22-3) afirma que a administração hoteleira abrange:

a) uma ação planejada das atividades em termos de tarefas e meios para realizá-las;

b) uma ação diretiva que envolve recrutar, admitir, movimentar, treinar etc.;

c) uma ação controladora de reservas, custos operacionais, entrada e saída de hóspedes, de faturas, roupas e caixas;

d) uma ação de equilíbrio entre os vários setores do hotel.

\subsection{Treinamento e Socialização dos Recursos Humanos}

\subsubsection{O Hotel Padrão de Comparação}

FRIEDMMAN (apud CHIVELLARI \& MELO, 1992:49) considera que a qualificação deve ser associada à habilidade profissional, aos conhecimentos profissionais ou técnicos, à inteligência profissional etc. Contrariamente, a não-qualificação corresponderia ao exercício de um trabalho simples, parcelado e repetitivo em que inexiste iniciativa, e a formação se limita à aprendizagem de rotinas e o treinamento se restringe à assimilação de gestos.

Para CHIVELLARI \& MELO (1992:50), oprocesso tecnológico influi no sistema de qualificação definindo não só um tipo de organização da produção, mas também a organização da empresa em terınos de funções, postos de trabalho, um tipo de divisão do trabalho, de coordenação, de gerência e de controle.

O processo de trabalho no hotel-parâmetro, administrado pela cadeia hoteleira Novotel (NHT - Hotelaria e Turismo) integrante da holding 
ACCOR, que abrange ainda as cadeias Parthenon, Ibis e Sofitel, obedece regras estabelecidas a distância pela sede e pelo escritório de São Paulo. Os dados obtidos acusaram particularidades tais como:

a) a definição clara das tarefas relativas a cada função pela matriz brasileira, sediada em São Paulo, que se reporta, por sua vez, a orientação da França;

b) conhecimento de toda a empresa pelo trabalhador de forma a possibilitar a rotatividade entre funções quando necessário;

c) ênfase na satisfação com o trabalho por parte dos empregados, a partir da internalização da máxima de que "empregado satisfeito resulta em serviço de qualidade e cliente satisfeito";

d) agilidade no funcionamento do hotel, em face da estrutura cnxuta e flexivel, dependente de centros de decisão externos.

A cadeia Novotel pauta sua atuação na valorização dos recursos humanos, e inculca, psicológica e ideologicamente, a disseminação dessa postura a todo o grupo. Logo que é admitido, o funcionário conhece o funcionamento da organização, de modo que pode substituir perfeitamente um colega que exerce função semelhante ou até outra função, além de internalizar todos os princípios do grupo.

Os gerentes são treinados de forma unificada no escritório de São Paulo, passando a ser instrutores dos chefes. Posteriormente, são realizadas avaliações de desempenho dos funcionários, através de formulários que são conhecidos como "barômetros".

Ao empregar-se no hotel, cada chefe recebe uma cartilha com as sete palavras-chave, os chamados "parafusos", que sintetizam a filosofia da marca Novotel. São elas: liberdade, simplicidade, regularidade, prestigio, preço justo, modernidade e reconhecimento. A idéia é que o empregado satisfeito expresse essa satisfação para o hóspede, o que demandará a longo prazo um aumento da clientela.

Recentemente, foi implantado o Banco de Talentos em São Paulo, que promove cursos desenvolvidos em três módulos:

a) pesquisa de carreira;

b) acompanhamento de desempenho;

c) perfil de competência gerencial.
Enfim, a NHT prioriza o treinamento de recursos humanos, em que predomina a internalização de regras estabelecidas a distância pelo sistema Novotel e a institucionalização de mecanismos de mediação, que podem ser traduzidos no hotel por remunerações acima dos salários do mercado de trabalholocal, estabilidade, uso de pontuação e premiação por produtividade, entre outros.

Pelo exposto, fica evidente que o hotel analisado faz parte do tipo de organização denominada como hipermoderna por PAGÉSET AL (1990), na qual os conflitos são previstos e antecipados, sendo usadas mediações integradas e um esquema de administração a distância, homogêneo, coerente e articulado.

\subsubsection{Os Hotéis Locais}

Nos demaishotéis pesquisados prevelecem as estruturas organizacionais do tipo divisional com setores e subsetores, que se articulam às cinco grandes áreas que tradicionalmente envolvem todos os serviços prèstados por um hotel de médio e grande porte: administração, hospedagem, alimentação e bebidas, e serviços complementares.

No hotel-padrão, embora estejam previstas todas as áreas mencionadas, as estruturas organizacionais não têm inúmcros desdobramentos, ou seja, não é acentuadamente hierarquizada; ao contrário do que acontece nos demais hotéis que possuem estruturas rígidas, hierarquizadas e amplas, o que dificulta o processo de trabalho e prejudica a qualidade dos serviços à medida que chegam a parcelar o trabalho sob a ótica taylorista. Assim, encontrou-se os mais variados organogramas com inúmeras chefias. Por exemplo:

a) Hotel 1: gerentegeral,gerentedevendas, governanta executiva, chefes de pessoal, recepção e lavanderia etc.;

b) Hotel 2: gerente geral, gerente de eventos, gerente de alimentos e bebidas, chefes de pessoal, manutenção, controle e tesouraria etc.

Presume-se que as estruturas são criadas conforme a formação dos profissionais mais especializados e/ou dos postos de trabalho que esses possam ocupar. Daí, os organogramas são elaborados. Como os empresários provêm de outros ramos econômicos, uma das estratégias mais utilizadas para contornar a problemática da tecnologia tem sido a contratação de profissionais especializados nas regiões Sul e Centro-Sul.Esses profissionais vêm de grupos hoteleiros tradicionais atuantes no país, como Horsa, Transamérica, Othon (que por sinal é de origem nordestina), dentre outros. 
A entrada dos demais empregados se dá com a aprendizagem de tarefas no próprio setor em que passam a trabalhar, caracterizando-se mais como uma "habituação" às tarefas que começam a executar, sob orientação da chefia imediata.

Observou-se que em Natal, como em outras capitais do Nordeste, a hotelaria absorve os trabalhadores excluídos de outros setores econômicos do mercado de trabalho, além daqueles oriundos de outros hotéis. Como $100 \%$ dos hotéis pesquisados em Natal pertencem a grupos empresariais ligados à construção civil, é comum encontrar ex-pedreiros, ex-serventes de pedreiros etc., exercendo funções de garçons, porteiros, entre outros.

Em geral, os profissionais mais especializados fizeram cursos no Serviço Nacional de Aprendizagem Comercial SENAC/CEATEL (São Paulo), hotéis-escolas do Brasil e do exterior e outros promovidos por entidades como American Express.

Não existe nenhuma política de recursos humanos nos hotéis pesquisados, e tampouco foi manifestada a preocupação em qualificar recursos humanos, embora a grande dificuldade citada por todos seja a inexistência de mão-de-obra qualificada no mercado.

Verificou-se nos hotéis locais que não há cautela com serviços que exteriorizem a identidade cultural do Nordeste, apesar da presença involuntária da hospitalidade nordestina e de valores culturais nos projetos arquitetônicos e de decoração dos empreendimentos. Contrariamente, o hotel- padrão tem autonomia para explorar a identidade regional, quer na composição do cardápio, quer na promoção de eventos culturais e até na decoração interna dos salões. E cumpre essa determinação.

\subsection{Relações de Trabalho: Hotel-Padrão x Hotéis Locais}

Se nas empresas de gnupos locais o "dono" (proprietário ou grupo) é visto como o "grande pai", devido às adversidades do mercado de trabalho da região Nordeste, no hotel que faz parte de um sistema multinacional, a organização é a grande empregadora, impessoal e distante. Enquanto no primeiro caso os conflitos são abertos e podem fluir confrontando empregador, chefias e empregados, no hotel-parâmetro os conflitos são "abortados", na proporção que ou transferem-se para uma esfera impessoal e distante (o escritório de São Paulo ou a sede na França) ou são previstos antecipadamente.

As "regras do jogo", estabelecidas pelo hotel da cadeia internacional, atendem muito mais à filosofia da empresa embutida na homogeneização do controle e muito menos às exigências do mercado de trabalho. O cumprimento das decisões da empresa se dá sem questionamentos. Evidentemente, essa adesão é mais forte no hotel-padrão, porque as regras antecipam os possiveis questionamentos.

As contradições do espaço econômico, social e político afetam indistintamente todos os hotéis pesquisados. Conforme depoimento do gerente geral do hotel-parâmetro, as principais dificuldades da mão-de-obra decorrem:

(...) da educação e formaçāo familiar deficitária e da ausência de escolas realmente qualificadas para o segmento hoteleiro.

Ora, enquanto o hotel-padrão se penalizaaté da pouca profissionalização dos empresários do setor e dos níveis de instrução e socialização primária dos empregados, que certamente obstaculizam a socialização da empresa, os demais hotéis acusam a dificuldade de encontrar mão-de-obra qualificada, mas nada fazem para mudar o quadro, tirando até proveito da situação. Esse proveito pode ser expresso nos baixos salários e nas dispensas nos períodos de baixa estação, que manifestam a sazonalidade inerente à hotelaria, além das vicissitudes comuns ao contexto social.

\section{CONCLUSÃO}

Não foi fácil o exercício de comparar uma organização que usa mediações homogêneas, econômicas, sociais e psicológicas planejadas e definidas, sistema decisório de autonomia controlada e detém tecnologia hoteleira com empresas hoteleiras cujosinvestimentos prescindiram a priori do conhecimento tecnológico.

Enquanto a organização padrão, como integrante de um sistema mundial, incorporou regras não somente de produção e comercialização, mas também de recursos humanos à tecnologia adotada, o que atendc a etapa do capitalismo denominada de neo-capitalismo, as empresas hoteleiras locais buscam numa tentativa de acerto e erro incorporar tecnologia em hotelaria. Se o mercado tem se mostrado favorável até o momento, o não-conhecimento do processo de trabalho em hotelaria e os reflexos das condições socioeconômicas da região Nordeste podem afetar dentro de pouco tempo essas organizações, comprometendo os investimentos realizados.

Essa fragilidade é mais visível quando se considera a chegada de grupos hoteleiros que influenciam determinantemente os fluxos turísticos mundiais e usam sistemas de gestão muito maissólidos, comobem exemplifica o estabelecimento do grupo Novotel aqui analisado. A lógica que norteia uma organização desse tipo é bem distinta da lógica dos hotéis pesquisados e isso, a longo prazo, pode comprometer a inserção desses últimos no mercado. 


\section{REFERÊNCIAS BIBLIOGRÁFICAS}

CASTELLI, Geraldo. 1982. O hotel como empresa. 2 ed. Porto Alegre: Sulina.

CHIAVASSA, Jorgina \& CHIAVASSA, Fernando. 1992. Revendo a história. Hotelnews, Rio de Janeiro, n. 243, p. 60-5.

CHIVELLARI, I Helena \& MELO, Marlene Catarina de O. 1989. Saber fazer: implicações da qualificação. Revista de Administração de Empresas, São Paulo, v. 29, n. 2, p. 47-62, abr.l jun.

EMBRATUR - Instituto Brasileiro de Turismo. 1991. Anuário Estatistico EMBRATUR - 1990/ 1991, Brasilia: Embratur, v. 20.

EMBRATUR - Empresa Brasileira de Turismo. 1987. Guia de investimento turisticos. Rio de Janeiro: Embratur.

FLEURY, Afonso \& VARGAS, Nilton. 1983. Aspectos conceituais. In: (org.). Organização do trabalho. Uma aborlagem interdisciplinar: sete casos brasileiros para estudo. São Paulo: Atlas.

FLEURY, Maria Tereza \& FISCHIER, Rosa Maria. 1983. Processo e relações de trabalho no Brasil. São Paulo: Atlas.

FOLHA DE SÃO PAULO. 1991. São Paulo, 24 out. Caderno 6, p.6.

GOMES, Luis Carlos Tabet. 1978. Situação atual do turismo no Brasil. Revista de Administração Paulista, São Paulo, n. 32.

IGNARRA, Luis Renato. 1989. Evolução econômica da hotelaria brasileira (1978/87). Boletim Técnico do SENAC, Rio de Janeiro, v. 15, n. 1, jan./abr.

MOTTA, Paulo Roberto. 1991. Gestão contemporânea: a ciência e a arte de ser dirigente. São Paulo: Record.

PAGÉS, Max et el. 1990. O poder das organizações. São Paulo: Atlas.

SILVA, Carlos Arildo Soares. 1990. Cierenciamento: algunscuidados fundanentais na administraÇão hoteleira. Hotel e Cia., n. 9, p. 22-3.

THIOLLENT, Michel. 1983. Problemas de metodologia. In: FLEURY, A. C. C. \& VARGAS, N. (org.). Organização do trabalho. Uma abordagem interdisciplinar: sete casos brasilerios para estudo. São Paulo: Atlas.

VARGAS, Nilton. 1983. Atecnologia e Deus ou diabo - Visões e conceitos de tecnologia. Ciência, Tecnoiogia e Desenvolvimento. Brasilia: CNPq/UNESCO.

RATTNER, 1980. Tecnologia e sociedade: uma proposta para os paises subdesenvolvidos. São Paulo: Brasiliense, $184 \mathrm{p}$. 